\title{
Semantic Approach and Agent-based Modeling for Electricity Demand Forecasting in the Regional Market
}

\author{
Elena V. Galperova ${ }^{1}$, Vasiliy I. Galperov ${ }^{2}$, Vagim I. Loktionov ${ }^{3}$ \\ ${ }^{1}$ Melentiev Energy Systems Institute of Siberian Branch of the Russian Academy of Sciences, \\ Lermontov str., 130 \\ Irkutsk, Russia \\ E-mail: galperova_e_v@mail.ru \\ ${ }^{2}$ Melentiev Energy Systems Institute of Siberian Branch of the Russian Academy of Sciences, \\ Lermontov str., 130 \\ Irkutsk, Russia \\ E-mail: galperov@gmail.com \\ ${ }^{3}$ Melentiev Energy Systems Institute of Siberian Branch of the Russian Academy of Sciences, \\ Lermontov str., 130 \\ Irkutsk, Russia \\ E-mail:vadlok@mail.ru
}

\begin{abstract}
The relevance of the paper is determined by the changes in the conditions of energy and economy development, that impose new requirements on the methodology of energy demand forecasting. The most important changes are happening to energy consumers. The consumers, as equal participants in the electricity market, will affect demand, prices and adaptability in the power system in future. The main reason to use semantic approach and agent-based modeling is impossibility to formalize direct and feedback connections between consumers and central power grid along with high uncertainty. Ontology and cognitive model of the regional energy system was designed. It allows to recognize and determine cause-effect relationships in different operating conditions of the regional energy system. The developed algorithm and model, based on the agent approach, make it possible to assess the possibilities and the strength of consumer behavior effect on the development of the regional power grid.
\end{abstract}

Keywords: Semantic approach, agent-based modeling, electricity demand, ontology.

\section{Introduction}

Today, in the world power industry, there are revolutionary changes, which were caused by the following challenges facing the world:

- increasing depreciation of the electric power infrastructure,

- appearing and development of distributed energy resources (including renewable energy resources),

- increase of environmental requirements,

- increase of electricity cost,

- fast electricity demand growth,

- increasing requirements for quality and reliability of energy supply,

- changing role of consumers in the energy system.

Experts see the solution to the challenges in the transition to the next energy structure, the main role in which will play integrated and united smart grid [1].
An important feature of the future energy sector is the orientation towards the needs of the end user. The client-oriented approach imposes new requirements to the methodology of energy demand long-term forecasting. Existing approaches, being based on the concept of centralized fuel and energy supply of consumers, focus on the national level [2-4]. Energy consumptions of regions are calculated, as a rule, by dividing the national volume of fuel and energy consumption into parts according to a regional consumption structure of the country. New conditions make researchers pay more attention to the consumers at regional level where energy producers and consumers protect their interests, forming the conjuncture of regional energy markets. It can require an iterative process between the regional and national levels and affect the structure of new generating capacities in the power industry. 
Controlled-load consumers are an important part of the smart grid. Any consumer (industrial enterprises, transport, service industry enterprises, households, etc.) can be controlled-load if it possible to control the amount of electricity, received from power grid, according to the information of prices, reliability, quality, and other parameters and to influence them by selling self-generated electricity [5,6]. Such consumer behavior not only affects demand and prices on regional energy markets, but also increases the level of adaptability of energy systems to changing development conditions.

Adaptability of the energy system is an ability of a system to adjust to changing external and internal conditions and to keep achieving its development goals. The goals could be the following ones: sufficient energy supply to the economy; formation of rational structure of electricity generating capacities; achievement of optimal volumes and directions of energy supplies to the region, etc. [7]. It is obvious that energy companies benefit from increasing in their adaptability, as it reduces risks and increases economic efficiency. In addition, the adaptability can be one of the criteria for making investment decisions and for assessment of the reliability of power industry [8].

The level of energy system adaptability is determined not only by recovery costs but also by the number of possible, accessible and effective options for the system to response to these changes: the more the number, the higher level of adaptability. The consumers, as equal participants in the electricity market, will help reduce peak loads, reserve capacities, fuel costs, losses, what will affect demand, prices and level of energy system adaptability in power industry [9].

\section{Literature review}

Modeling the behavior of energy consumers has become very relevant in recent years. In the world, one of the main research topics is demand management in households, depending on the electricity price, to reduce self-consumption costs. The paper [10] considers the ways of reducing the consumption of the most energyintensive devices in the peak part of the daily load schedule. In [11] researchers offer to carry out selfconsumption and self-generated electricity for days ahead on the basis of economic parameters optimization, whereas in [12] researchers suggest doing the same on the basis of technical parameters. In [13] authors estimate the comparative efficiency of distribution of self-generated electricity between electrical appliances and storages. The approach presented in [14] assumes the maximum benefit from the rationalization of energy consumption for each consumer from the group of households, which have one energy source, and in [15] for the group of households as a whole. In [16] authors model and analyze a load schedule of each consumer in a group and asses the influence of their interaction on the voltage in the network.

The Russian researchers solve the problem of optimization of daily schedules of the operating modes of devices and equipment both for households [17] and industrial enterprises [18]. In the paper [19], the issues of coordination interaction between consumers and power grid for regulation daily load schedules are considered.

The main goal of the mention papers is to achieve satisfactory results in real-time demand management for both an individual consumer and a group of consumers. Such researches are not enough for forecasting, as it should answer the following the question: how will optimization of self-consumption and self-generated electricity affect the overall electricity demand, the structure of generating capacities in the electric power grid, and its adaptability. It should be noted that changing of electricity demand affect demand for other types of energy resources in the regional energy market.

The purpose of this paper is a development of longterm forecasting methodology to assess the influence of controlled-load consumer behavior on electricity demand and the structure of generating capacities in a regional power system. The main difficulties in analysis and simulation of this influence are the following ones: (1) multidimensionality and interconnectedness of the electricity market; (2) high uncertainty of indicators, factors and relationships in the development of the electricity market; (3) a nonstationary nature of changes in the process of the electricity market development over time. Authors propose to apply a semantic approach and agent-based modeling to overcome the difficulties in simulation of power system development, that are associated with high uncertainty and impossibility to formalize grid-consumer connections.

\section{The proposed method}

It is supposed that the regional power system consists of a centralized power grid and a set of consumers. The centralized power grid consists of a set of large electric power plants with different types of used fuels (coal, gas, nuclear, etc.), technologies and economic indicators (fuel consumption, cost, etc.). The change in the share 
of each power plant in total electricity production affects electricity price in the centralized power grid.

For the study it is necessary to divide all energy consumers into the following several types:

(a) stable (passive) consumers, which can't change its energy consumption, because of technological and other peculiarities;

(b) controlled-load consumers, which able to change (reduce) its energy consumption;

(c) prosumers, which have demand management, self-generated capacities and energy storage batteries, as well as possibility to sell the electricity to the centralized power grid.

The volume of electricity used in the regional market is composed of the needs of all consumers

$$
V_{r}=V_{s}+V_{a}+V_{p}
$$

Where $V_{s}$ - the need for electricity of stable consumers, $\mathrm{kWh} ; V_{a}$ - the need for electricity of controlled-load consumers, $\mathrm{kWh} ; V_{p}$ - the need for electricity of prosumers, $\mathrm{kWh}$.

Stable consumers do not have ability to influence on electricity demand in a regional power system because of constant consumption

$$
V_{s}=\text { const }
$$

The controlled-load consumers try to optimize selfconsumption and minimizing energy costs.

$$
\begin{gathered}
V a_{\min } \leq V_{a} \leq V a_{\max } \\
V_{a}=\sum_{i=1}^{n} e_{i} h_{\mathrm{i}} \\
3=c^{t} V_{a} \rightarrow \min
\end{gathered}
$$

Where 3 - electricity costs, $c^{t}$ - electricity price for production structure $t$ in the centralized power grid, $e_{i}$ the power of each device (air conditioners, heaters, water heaters, ovens, lamps, etc.) of $i$-th consumption process (lighting, heating, cooling, power, etc.), $n$ number of devices, $h_{i}$ - hours of device operation.

For the prosumers, it is necessary to find such combination of both received and self-generated electricity for self-consumption, the cost of which should not exceed the specified level $\overline{3}$, including income from the electricity sold to the centralized power grid.

The following situations are possible:

- All electricity comes from a centralized power grid

$$
c^{t} V_{p} \leq \overline{3}
$$

- $\quad$ Electricity comes both from centralized power grid and from self-generation

$$
\alpha c^{t} V_{p}+(1-\alpha) V_{p} s-d \leq \overline{3}
$$

where $\alpha$ - share of purchased electricity in total consumption, $s$ - cost of self-generated electricity.

- The prosumer fully provides self-generated electricity

$$
\sum_{j} s_{j} N_{j} h_{j}-s V_{p}+d \leq \overline{3}
$$

$N_{j}$ - power of all self-generating capacities $j, h_{j}-$ hours of operation of self-generating capacity $j, s_{j}-$ electricity cost of each self-generated capacity $j$.

In this case,

$$
\sum_{j} N_{j} h_{j} \geq V p
$$

In the last two cases, the consumer can sale the electricity surplus to the centralized power grid and receive revenue $d$.

We use possibilities of semantic approach for simulation of relationships in the regional power system. Given increasing uncertainty and impossibility of formalization of consumer-grid relationships, semantic modeling allows us to design ontology and to describe the domain area as a set of concepts and relations between them [20] (fig. 1).

The basis for construction ontology is the following information:

- In a region there is a centralized power grid consists of a set of large electric power plants with their technical and economic parameters,

- The goal of a centralized power grid is to maximize production,

- There are a set of industrial and non-industrial energy consumers of different types,

- Consumers buy electricity from a centralized power grid,

- The purpose of consumers is to minimize cost of self-consumption,

- $\quad$ Prosumers can use self-generated electricity for self-consumption, storage or sell it to a centralized power grid.

Controlled-load consumers and prosumers can change energy self-consumption volume if cost of electricity in a centralized power grid does not suit them. It is the reason to reduce consumption volume of electricity received from centralized power grid and to use self-generation capacity. New relationships, shown in the ontology by dotted lines, appear in this case.

Being directed graphs, cognitive models are used to describe cause-effect relationships. In a cognitive model (fig. 2), vertices are the objects of the regional electric power system, and edges are the connections between them. In the proses of construction the cognitive model, it was found that the relationship between such 


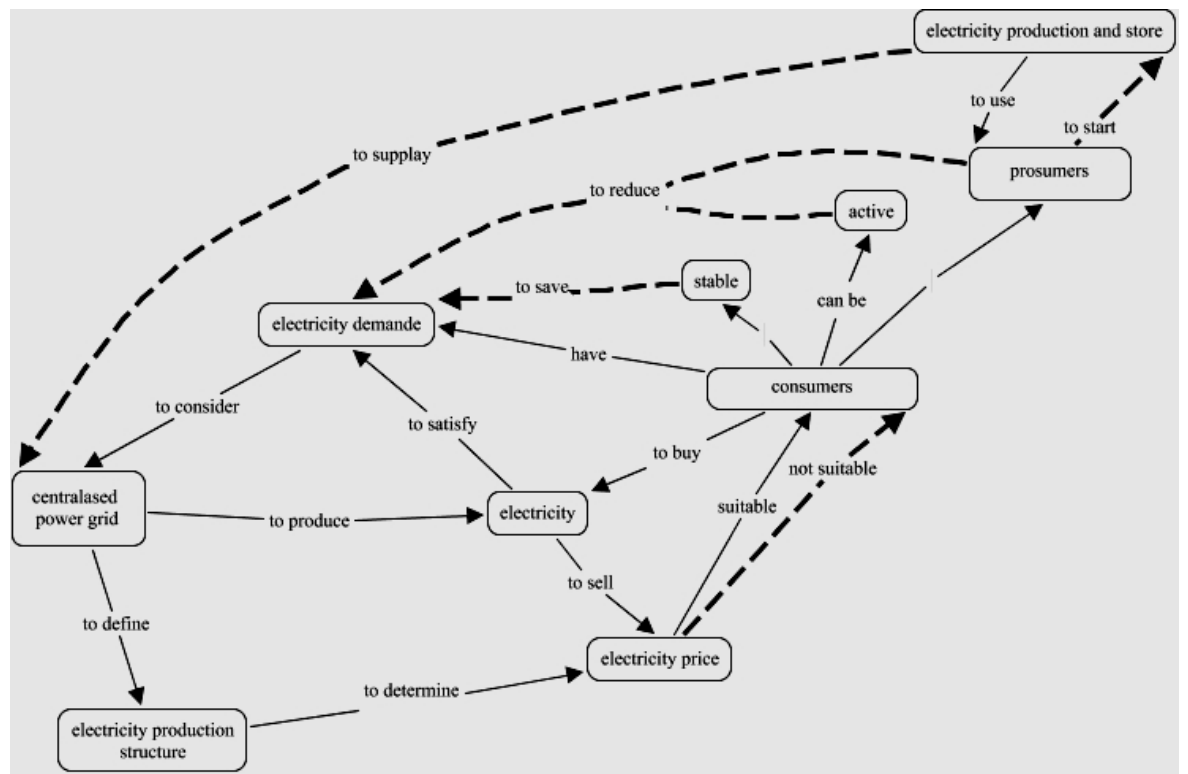

Fig. 1. Ontology of the regional power system in terms of changing electricity price.

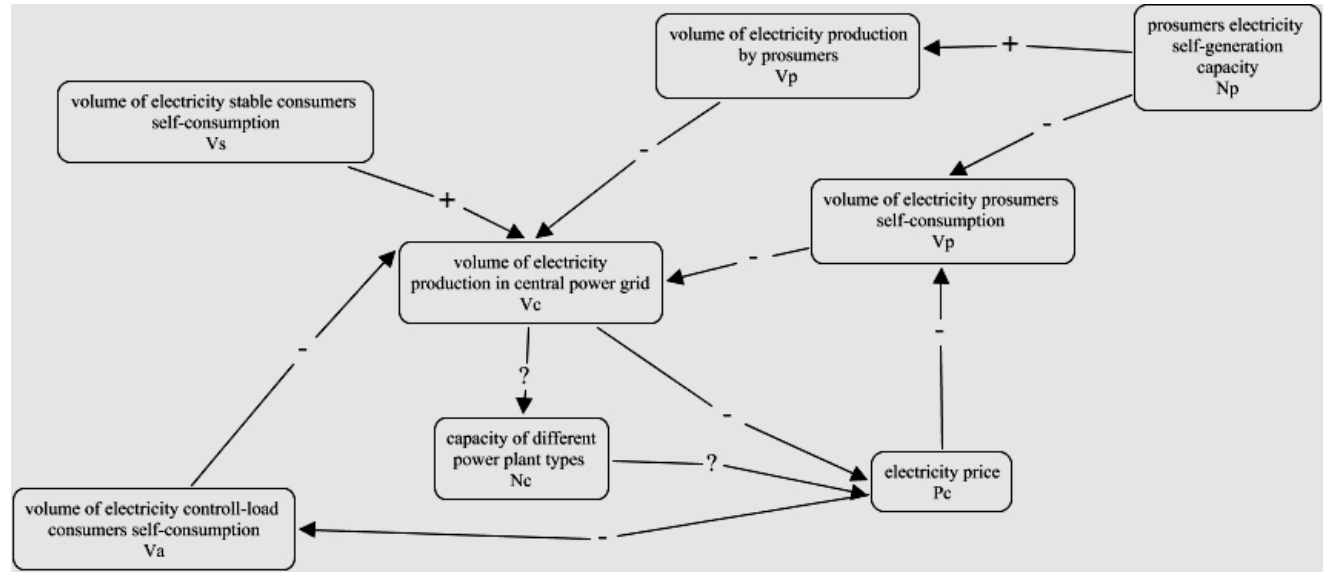

Fig. 2. Cognitive model of the regional power system.

indicators as volume of electricity production in the centralized power grid $\left(V_{\mathrm{c}}\right)$, capacity of different types of power plants $\left(N_{\mathrm{c}}\right)$, and the price of electricity $\left(P_{\mathrm{c}}\right)$ is determined ambiguously and depends on the situation in a region. To determine this relationships, it is necessary to do additional calculations by following the algorithm (fig. 3):

- The maximum level of electricity demand in the regional energy system is calculated as the sum of all energy self-consumptions (demand of all stable consumers is the constant part of the demand),

- Determine priority of power consuming processes and amount of possible reduction of selfconsumption for each controlled-load consumer and prosumer,

- The structure of electricity production and its price in the centralized power grid are determined by optimization by criteria of minimum cost of $1 \mathrm{kWh}$ to meet the estimated maximum electricity demand,

- Controlled-load consumers and prosumers optimize self-consumption in accordance with the calculated electricity price in the centralized power grid and determine possible demand reduction and a new level of energy consumption for the centralized power grid,

- Under new conditions new production structure is optimized in the centralized power grid and new electricity price is calculated,

- Iterative calculations process stops when all prosumers fully switch to self-generated electricity. Then the electricity demand volume is calculated. The magnitude of decrease from the 


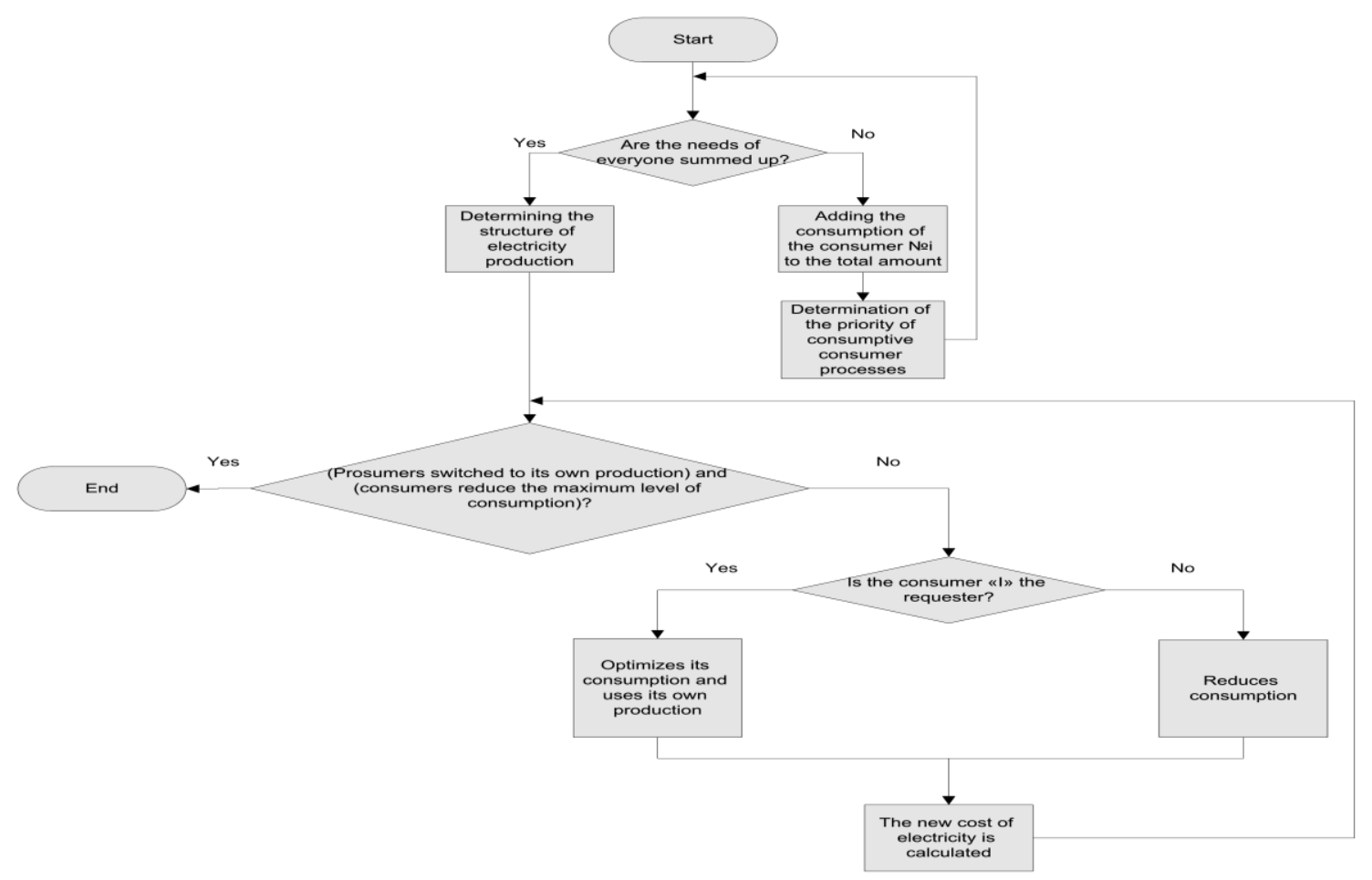

Fig. 3. Algorithm to study the impact of controlled-load consumer behavior on electricity demand in the regional power system.

maximum demand volume is estimated and analyzed.

Agent-based approach was chosen to simulate all the objects and their relationships in a regional power system. This approach allows modeling the most complex nonlinear direct and feedback links with any necessary level of detail and abstraction [21].

The multi-agent model of a centralized power grid is under development now. In such model, each power plant represents an agent, which could optimize its technical and economic indicators.

Previously developed prototype of the multi-agent model of prosumer is described in [22]. Being based on a typical multi-agent system, this model consists of a set of agents [23], which represent behavior of the prosumers. Each agent describes the operation possibility of an individual power-consuming or generating device. The agent-manager carries out control over the operation of each device-agent and the coordination of processes of their behavior. This agent contains descriptions of all possible scenarios for the mutually agreed behavior of the self-consuming and self-generation processes and relations with the centralized power grid. Depending on the situation in the centralized power grid, it controls self-consumption and self-generation to implement a scenario that corresponds to its interests. Using the apparatus of
Joiner-networks, each specific scenario could be described as an event model [24].

\section{Conclusion}

The changes in the paradigm of energy sector development based on the concept of Smart grid and the growing uncertainty of national and region economy impose new requirements on the methodology of longterm energy demand forecasting.

The consumers, as equal participants in the electricity market, will affect both demand and prices in the power system in future.

Semantic approach allows us to overcome the difficulties in modeling power system development that are associated with high uncertainty and impossibility to formalize grid-consumer relationships.

The developed algorithm and model, based on the agent approach, make it possible to assess impacts of consumer behavior on the structure and operating conditions of the regional power grid.

\section{Acknowledgements}

The reported study was funded by state task III.17.5.2, № AAAA-A17-117030310452-7 and by RFBR according to the research projects №16-06-00230, №1607-00474, №17-06-00102. 


\section{References}

1. Energy Technology Perspectives 2017. Catalysing Energy Technology Transformations. International Energy Agency, ( www.iea.org/etp2017)

2. S. P. Filippov, Energy forecasting using a complex adaptive simulation models, Bulletin of RAS. Energy Series. 4 (2010) 41-55.

3. The National Energy Modeling System / Industrial Demand Module Washington: Energy Information Administration.

http://www.eia.gov/forecasts/aeo/assumptions/pdf/industr ial.pdf

4. B. Chateau and B. Lapillonne, The MEDEE Approach: Analysis and Long-term Forecasting of Final Energy Demand of Country, in Energy Modelling Studies and Conservation: Proceedings of a Seminar of the United Nations Economics Commission for Europe (Elsevier, Washington D.C., 1982), pp. 57-67.

5. B. B. Kobets and I. O. Volkova, Innovative development of electric power industry based on the SMART GRID concept (IAC Energy, Moscow, 2010).

6. V. A. Stennikov, Integrated Intelligent Power Systems, http://isem.irk.ru/upload/iblock/cef/cef1938237b98ee723 192b6676049d89.pdf

7. V. A. Smirnov, Adaptation processes in energy development (Science, Moscow, 1983).

8. V. I. Loktionov, Adaptability of energy systems development options as an indicator of energy security, Economic Analysis: Theory and Practice. 40 (2015) $11-21$.

9. F. V. Veselov and A. V. Fedosova, SmartGrid - smart answer to the challenges of "smart" economy, The energy market. 5 (2011) 52-58.

10. Ning Zhanng, L. F. Ochoa and D. S. Kirschen, Investigating the impact of demand side management on residential customer, in IEEE PES Innovative Smart Grid Technologies Europe (Manchester, UK, 2011), 7 p.

11. Juan M. Lujano-Rojas, Claudio Monteiro, Rodolfo DufoLopez and Jose L. Bernal-Agustin, Optimum residential load management strategy for real time pricing demand response programs, Energy Policy. 45 (2012) 671-679.

12. Amir-Hamed Mohsenian-Rad and Alberto Leon-Garcia, Optimal Residential Load Control With Price Prediction in Real-Time Electricity Pricing Environments, IEEE Trans. on Smart Grid. 1 (1) (2010) 120-133.

13. Nikhil Gudi, Lingfeng Wang and Vijay Devabhaktuni, A demand side management based simulation platform incorporating heuristic optimization for management of household appliances, Electrical Power and Energy Systems. 43 (2012) 185-193.

14. Amir-Hamed Mohsenian-Rad, Vincent W.S. Wong, Juri Jatskevich, Robert Schober and Alberto Leon-Garcia,
Autonomous Demand Side Management Based on Game-Theoretic Energy Consumption Scheduling for the Future Smart Grid, IEEE Trans. on Smart Grid. 1 (3) (2010) 320-331.

15. Bingnan Jiang and Yunsi Fei, Dynamic Residential Demand Response and Distributed Generation Management in Smart Microgrid with Hierarchical Agents, Energy Procedia. 22 (2011) 76-90.

16. Kumarsinh Jhala, Balasubramaniam Natarajan and Anil Pahwa, Prospect Theory based Active Consumer Behavior Under Variable Electricity Pricing, IEEE Transactions on Smart Grid. - PP(99):1-1 • 03/2018. 12 p. DOI:10.1109/TSG.2018.2810819, https://www.researchgate.net/publication/323501905_Pro spect_Theory_based_Active_Consumer_Behavior_Under _Variable_Electricity_Pricing

17. I. O. Volkova, M.V. Gubko and E. A. Salnikova, Active consumer: problem of joint optimization of energy consumption and local generation, Problems of management. 6 (2013) 53-61. (in Russian).

18. N. I. Voropai, Z. A. Stychynski, E. V. Kozlova, V. S. Stepanov and K. V. Suslov, Optimization of the daily load graphs of active consumers, Bulletin of RAS. Energy Series. 1 (2014) 84-90. (in Russian).

19. N. I. Aizenberg, E. V. Stashkevich and N. I. Voropai, Coordination of the interaction between electricity supply company and active consumers in the optimization of daily load schedules, Bulletin of RAS. Energy Series. 3 (2016) 44-54. (in Russian).

20. L. V. Massel and A. G. Massel, Intelligent computing in research areas of energy development, Bulletin of the Tomsk Polytechnic University: Management, computer science and engineering. 321 (5) (2012) 135-141. (in Russian).

21. V. N. Sidorenko and A.V. Krasnoselsky, Simulation modeling in science and business: approaches, tools, application, Business Informatics. 2 (08) (2008) 52-57. (in Russian).

22. E. V. Gal'perova and V. I. Gal'perov, Modeling the active consumer behavior based on the agent approach, Informational and mathematical technologies in science and management. 4 (8) (2017) 28-38. (in Russian).

23. L. V. Massel and V.I. Gal'perov, Development of a multi-agent system for assessing the state of electric power systems using event models, Science and Education. 9 (2015) Moscow: MSTU them. Bauman. El. № FSC77-4211. ISSN 1994-0448. DOI: 10.7463 / 0915. 0811180. (in Russian).

24. L. N. Stolyarov and K.V. Novik, Joiner-network for modeling interacting parallel processes, in Modeling of control processes: Sat. scientific works (Moscow. fiz.tech. in-t, Moscow, 2004) pp. 81-97. (in Russian). 